\title{
Decolorization of Remazol Brilliant Violet $5 R$ and Procion Red MX-5B by Trichoderma Species
}

\author{
Vanessa Jane Zainip ${ }^{1 *}$, Liyana Amalina Adnan², Mohamed Soliman Elshikh³ \\ ${ }^{1}$ Faculty of Engineering, Universiti Teknologi Malaysia \\ ${ }^{2}$ Kolej GENIUS Insan, Universiti Sains Islam Malaysia, Bandar baru Nilai, Nilai 71800, Malaysia \\ ${ }^{3}$ Department of Botany and Microbiology, College of Sciences, King Saud University, P.O. Box 22452, Riyadh 11495, Saudi \\ Arabia \\ * Correspondence: vanessajane92@gmail.com
}

SUBMITTED: 27 August 2021; REVISED: 15 October 2021; ACCEPTED: 15 October 2021

\begin{abstract}
Industrial wastewater including dye waste disposal, has been released in a massive amount and is difficult to degrade, especially synthetic dyes. In this study, 10 different types of fungi were isolated from a decayed wood in UTM forest and were labelled as S1-S10. Two dyes were chosen for this study, which were Procion Red MX-5B (PRMX5B) and Remazol Brilliant Violet 5R (RBV5R). These fungi were screened for their ability to decolor both dyes and further tested for their ability to decolor the dyes in liquid medium under several parameters; carbon and nitrogen sources, initial $\mathrm{pH}$ value, temperature, and agitation. S1 decolorized PRMX5B efficiently with the addition of glucose (45\%), ammonium nitrate $(61 \%)$, pH 3 (69\%), temperature $37^{\circ} \mathrm{C}(49 \%)$, and agitation $100 \mathrm{rpm}(69 \%)$, whereas S2 decolorized efficiently with the addition of glucose (60\%), ammonium nitrate (49\%), pH $3(70 \%)$, temperature $37^{\circ} \mathrm{C}(46 \%)$, and agitation $100 \mathrm{rpm}(74 \%)$. S1 demonstrated efficient decolorization of RBV5R with the addition of glucose $(80 \%)$, ammonium nitrate $(62 \%), \mathrm{pH} 3$, temperature $37^{\circ} \mathrm{C}(75 \%)$, and agitation $100 \mathrm{rpm}(90 \%)$, whereas $\mathrm{S} 2$ demonstrated efficient decolorization with the addition of glucose (52\%), ammonium nitrate $(67 \%), \mathrm{pH} 3$, temperature $37^{\circ} \mathrm{C}(75 \%)$, and agitation $100 \mathrm{rpm}(71 \%)$. The percentage of decolorization of dyes was measured by using a UV-Vis spectrophotometer. These fungi were then identified using the 18sr RNA method. Based on macroscopic and microscopic characteristics and a polygenetic tree, fungi S1 belong to Trichoderma koningiopsis and fungi S2 belong to Trichoderma atroviride.
\end{abstract}

KEYWORDS: Decolorization; filamentous fungi; Trichoderma koningiopsis; Trichoderma atroviride

\section{Introduction}

Dye is a natural or synthetic substance used to change or add any colour to something. This is widely used around the world, with over 10,000 different dyes used in industry and over $7 \mathrm{x}$ 105 tonnes of synthetic dyes produced annually [1]. Moreover, the consumption of synthetic dyes keeps increasing proportionally to the product demand. Thus, the untreated dye waste that is discharged into the rivers, lakes, or ponds will lead to water pollution. This is because the presence of very small amounts of dyes, such as at a low concentration of less than $1 \mathrm{mg} / \mathrm{l}$, is 
highly visible and immediately affects the ecosystem [1,2]. There are several ways to decolorize dyes that include physical, biological, and chemical processes such as membrane filtration and absorption, and electrocoagulation. Adsorption is a well-known equilibrium separation process and an effective method for water decontamination applications. Although the removal of dye using chemical methods can give positive results, the accumulation of concentrated sludge creates a disposal problem. Another responsibility problem occurs. Compared to biological methods, this method was the lowest-cost alternative. This is because it is commonly applied to treat industrial waste due to its ability to accumulate and degrade different pollutants $[3,4]$. The most recognisable contaminant in a waste stream, except all the rubbish is colour. This is due to the fact that even with a low concentration of synthetic dyes in water $(1 \mathrm{ppm})$, they are highly visible and thus have an impact on the environment.It prevents the aesthetic quality of surface water from being affected and affects the aquatic ecosystem because light penetration is reduced. This will reduce the photosynthesis process among the aquatic life because of the less light penetration. Thus, it is very important to create an effective treatment to overcome and reduce the colour in effluent wastes [2,4]. The objectives of this study are to screen, isolate, and identify fungi screened from nature that have the ability to decolorize RBV5R and PRMX5B, and to investigate the effect of different parameters on the decolorization process.

\section{Materials and Methods}

\subsection{Chemicals and Dyes}

RBV5R and PRMX5B were purchased from Sigma-Aldrich Co., Ltd. (USA) at the highest purity available. Table 1 shows their chemical structure and their properties. Merck (Darmstadt, Germany) purchased malt extract agar and glucose. All the other chemicals were purchased from Qrec Co. Ltd (New Zealand).

Table 1. Properties of RBV5R and PRMX5B

\begin{tabular}{|c|c|c|}
\hline Properties & RBV5R & PRMX5B \\
\hline Structure & 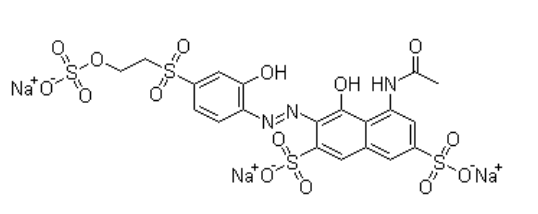 & \\
\hline Another name & Reactive Violet 5 (RBV 5R) & Reactive Red 2 \\
\hline Molecular formula & $\mathrm{C}_{20} \mathrm{H}_{16} \mathrm{~N}_{3} \mathrm{Na}_{3} \mathrm{O}_{15} \mathrm{~S}_{4}$ & $\mathrm{C}_{19} \mathrm{H}_{10} \mathrm{C}_{12} \mathrm{~N}_{6} \mathrm{Na}_{2} \mathrm{O}_{7} \mathrm{~S}_{2}$ \\
\hline $\begin{array}{l}\text { Molecular weight } \\
\text { Melting point }\end{array}$ & $\begin{array}{l}735.59 \text { gmol-1 } \\
>360^{\circ} \mathrm{C}\end{array}$ & $\begin{array}{l}615.34 \text { gmol-1 } \\
>300^{\circ} \mathrm{C}\end{array}$ \\
\hline Function & $\begin{array}{l}\text { Usually used for cotton, silk and linen } \\
\text { dyeing and printing, also suitable for } \\
\text { discharge printing }\end{array}$ & $\begin{array}{l}\text { Mainly used for cotton, wool, silk, } \\
\text { also can be used to knot dyeing. Its } \\
\text { storage stability is poor }\end{array}$ \\
\hline
\end{tabular}

\subsection{Microorganisms and Growth Conditions}

Ten different types of fungi were collected from the areas of Universiti Teknologi Malaysia, Johor Bahru, Malaysia. These fungi were stored in the refrigerator to preserve their growth. The selected fungi were cultured in malt extract agar and incubated for 7 days. Two agar plugs were cut from the fungus mycelium that grows in agar medium and placed into a conical flask 
to study the decolorization of dye. The flasks were incubated for 4,8 and 12 days, and the decolorization was monitored using a UV/VIS Spectrophotometer. All experiments were performed in duplicate to obtain a valid result. Agar powder $(2 \mathrm{~g})$ and yeast extract $(2 \mathrm{~g})$ were weighed and added to $40 \mathrm{~mL}$ of distilled water. The solution was then sterilized together with the petri dish and another apparatus for 60 minutes. After that, chloramphenicol $(3 \mathrm{mg})$ was added into the solution [5]. The sterilized petri dish was placed in laminar flow and $20 \mathrm{~mL}$ of malt extract solution was poured into each petri dish under fluorescent light. Then, the selected fungi are taken using a cork borer before being placed on solidified agar medium. Then the petri dish was sealed with parafilm [5].

\subsection{Batch studies}

Glucose $(0.8 \mathrm{~g})$ and yeast $(0.8 \mathrm{~g})$ were added to $40 \mathrm{~mL}$ of distilled water in the conical flask before being autoclaved for 60 minutes. After that, chloramphenicol (12 mg) was added and the selected fungi were cut from fully grown ME agar medium before being added into conical flasks. The mouths of the conical flask were covered with aluminium foil. Various parameters were conducted in this study on the decolorization of dye, such as carbon sources (glucose, fructose and galactose), nitrogen sources (yeast extract, ammonium nitrate and ammonium sulphate), $\mathrm{pH}(3,4,5$ and 6$)$, temperature $\left(20^{\circ} \mathrm{C}, 27^{\circ} \mathrm{C}\right.$ and $\left.37^{\circ} \mathrm{C}\right)$ and agitation $(100 \mathrm{rpm})$. The decolorization was monitored using a Nanocolor UV/VIS Spectrophotometer at 4, 8, and 12 days. The liquid culture was filtrated and centrifuged at $4000 \mathrm{rpm}$ for 30 minutes. After that, the supernatant was collected for further tests. Decolorization was monitored by scanning the absorbance between $400 \mathrm{~nm}$ and $800 \mathrm{~nm}$ using a Nanocolor UV/VIS Spectrophotometer. The maximum absorption of RBV5R was recorded at $558.1 \mathrm{~nm}$ while PRMX5B was at $533.1 \mathrm{~nm}$. The decolorization percentage of RBV5R and PRMX5B was calculated as follows:

Decolourization $(\%)=\frac{C_{0}-C_{f}}{C_{0}} \times 100 \%$

Where $\mathrm{C}_{0}$ is the absorbance of the dye as the initial experiment and $\mathrm{C}_{\mathrm{f}}$ is the absorbance of the dye after decolorization.

\section{Results and Discussion}

\subsection{Identification of fungi}

Table 1. Decolorization of test dye on solid medium by fungi screened from nature.

\begin{tabular}{cc}
\hline Species & Decolorization (\%) \\
\hline S1 & 98.5 \\
S2 & 97.5 \\
S3 & ND \\
S4 & ND \\
S5 & 17.5 \\
S6 & 12.6 \\
S7 & 16.2 \\
S8 & 10.5 \\
S9 & 56.5 \\
S10 & 63.2 \\
\hline
\end{tabular}

Ten different types of fungi were collected from the areas of UTM and labelled as S1-S10. Two samples were selected among these 10 different fungi based on their ability to decolorize 
PRMX5B and RBV5R (Table 1). Two samples (S1 and S2) were sent to $1^{\text {st }}$ Base for identification and phylogenetic trees for both selected fungi were obtained. The Basic Local Alignment Search Tool (BLAST) was used to determine the similarity between the two. Figure 1 and Figure 2 show the mycelia and polygenetic tree of an isolated fungi strain.
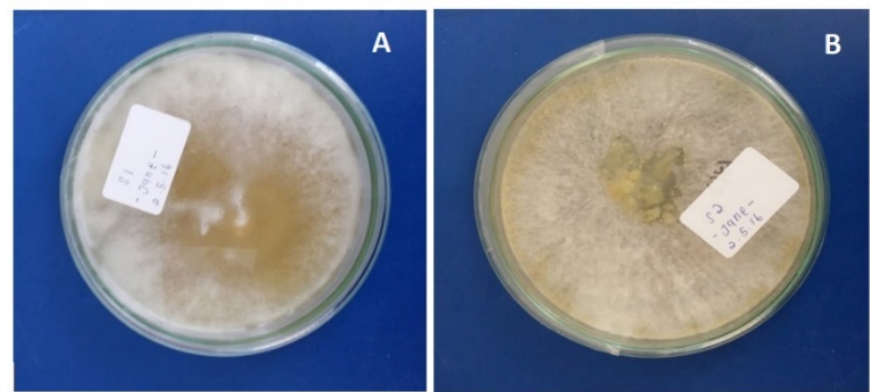

Figure 1. Mycelia of Trichoderma koningiopsis (A); Trichoderma atroviride (B)

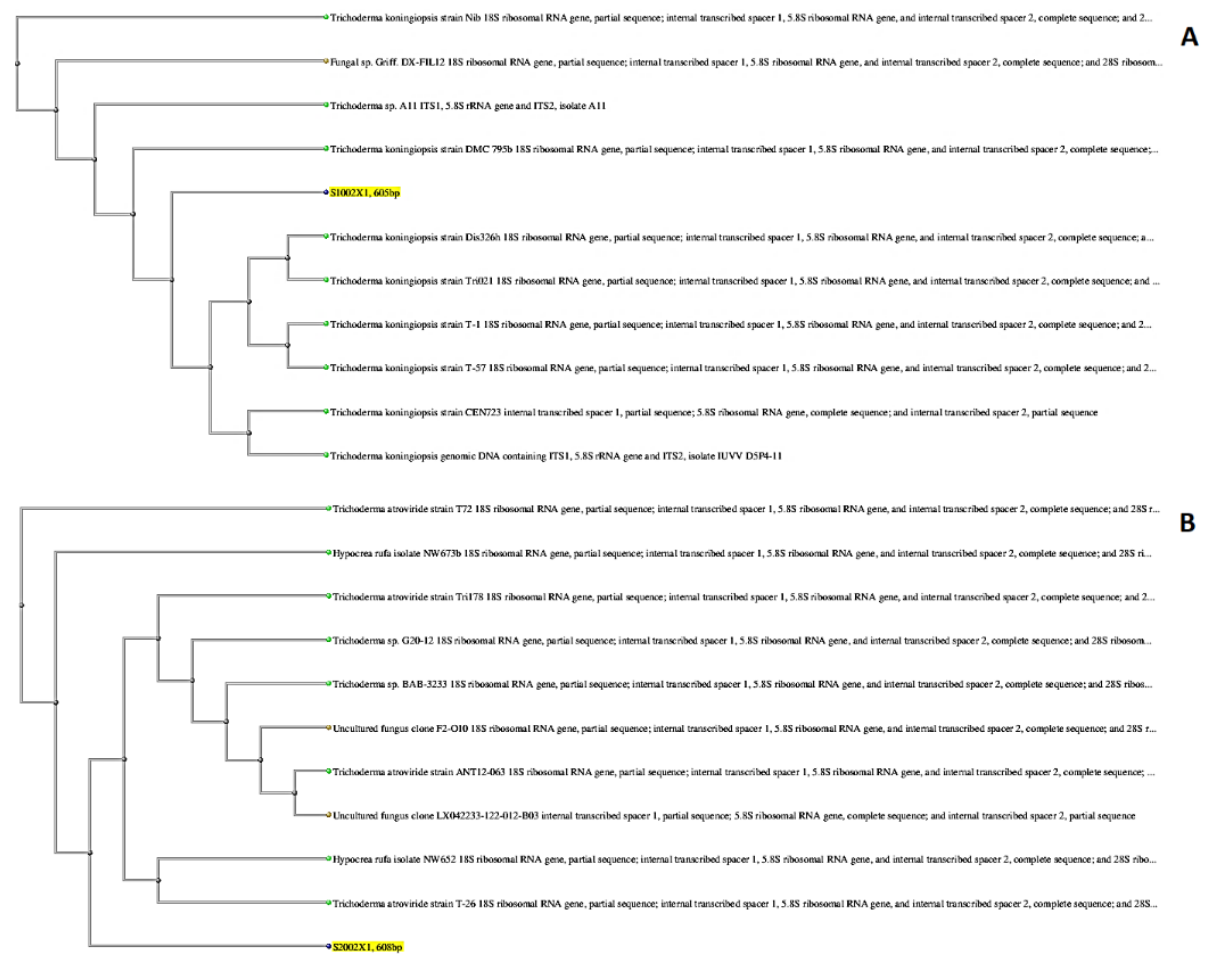

Figure 2. Phylogenetic tree of isolated fungi strain: Trichoderma koningiopsis (A); Trichoderma atroviride (B).

\subsection{Batch studies}

Figure 3A and 3B show Trichoderma koningiopsis and Trichoderma atroviride have the highest percentage of PRMX5B decolorization, which are $45 \%$ and $60 \%$ with glucose as a carbon source after 12 days of incubation. Other carbon sources such as fructose and galactose also show an increased decolorization within the incubation days. It can be observed that with fructose acting as another carbon source, Trichoderma koningiopsis and Trichoderma atroviride decolor the dye up to $32 \%$ and $46 \%$, while using galactose, both Trichoderma koningiopsis and Trichoderma atroviride decolor the dye up to $42 \%$. While for Remazol Brilliant Violet 5R, Figure 3C shows Trichoderma koningiopsis decolor dye using glucose, fructose, and galactose up to $80 \%, 78 \%$, and $75 \%$ respectively within 12 days of incubation. 
Figure 3D shows Trichoderma atroviride also has the highest percentage of decolorization with glucose as its carbon source, which is $52 \%, 40 \%$ (fructose) and $46 \%$ (galactose) after 12 days of incubation. Trichoderma koningiopsis and Trichoderma atroviride took glucose as a carbon source as well as nutrients for their growth. This is because glucose has a simpler structure that makes it easier to degrade and most readily usable by fungi. In addition, glucose gives high laccase activity [6,7].
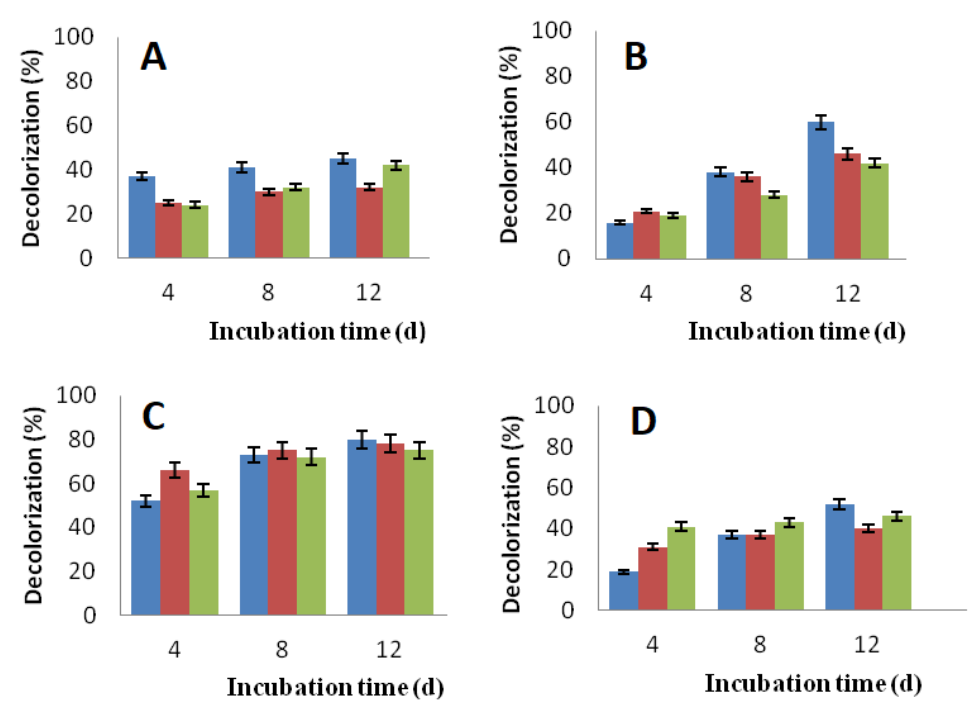

Glucose $\square$ Fructose Galactose

Figure 3. Effect of carbon source in decolorization of PRMX5B by Trichoderma koningiopsis (A), and Trichoderma atroviride (B); and RBV 5R by Trichoderma koningiopsis (C) and Trichoderma atroviride (D).

Two different species of fungi, Trichoderma koningiopsis and Trichoderma atroviride, were chosen to investigate their ability to decolor PRMX5B and RBV5R dye using three nitrogen sources such as yeast extract, ammonium nitrate and ammonium sulphate for 12 days of incubation. Figure 4 shows the percentage of decolorization of PRMX5B and RBV5R dye by Trichoderma koningiopsis and Trichoderma atroviride. For PRMX5B dye, Trichoderma koningiopsis and Trichoderma atroviride have the highest percentage of decolorization, which are $40 \%$ and $45 \%$ with yeast extract as a nitrogen source after 12 days of incubation. Other nitrogen sources such as ammonium nitrate and ammonium sulphate also show an increased decolorization within the incubation days given. It can be observed that with ammonium nitrate acting as another nitrogen source, Trichoderma koningiopsis and Trichoderma atroviride decolor the dye up to $61 \%$ and $49 \%$, while using ammonium sulphate, both Trichoderma koningiopsis and Trichoderma atroviride decolor the dye up to $46 \%$ and $38 \%$. While Trichoderma koningiopsis decolorized dye using yeast extract, ammonium nitrate and ammonium sulphate up to $60 \%, 62 \%$, and $51 \%$ respectively within 12 days of incubation, Trichoderma atroviride also has the highest percentage of decolorization with yeast extract as their nitrogen source, which are 56\%, 67\% (ammonium nitrate) and 58.6\% (ammonium sulphate) after 12 days of incubation. From the data obtained, it shows that ammonium nitrate has the highest percentage of decolorization for nitrogen source for Trichoderma koningiopsis and Trichoderma atroviride between both dyes compared to yeast extract and ammonium sulphate. This is because forest soils contain ammonium and nitrate, and it's assumed that ammonium is the major form of inorganic nitrogen that is taken up by fungi and other soil 
microorganisms [8]. Both these fungi have the ability to decolor the dyes and use ammonium nitrate as a nutrient because it was collected in the natural environment.
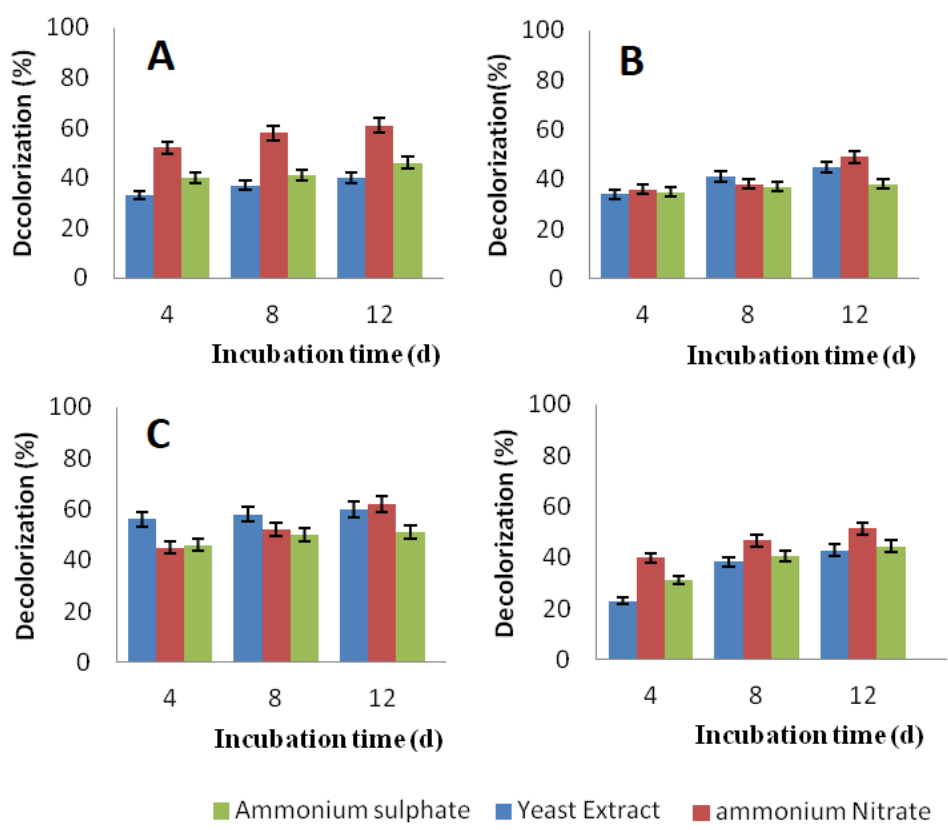

Figure 4. Effect of nitrogen source in decolorization of PRMX5B by Trichoderma koningiopsis (A) and Trichoderma atroviride (B); and RBV5R by Trichoderma koningiopsis (C) and Trichoderma atroviride (D).

Figure 5A and 5B show the percentage of decolorization of PRMX5B by Trichoderma koningiopsis and Trichoderma atroviride at different values of $\mathrm{pH}(\mathrm{pH} 3, \mathrm{pH} 4, \mathrm{pH} 5$, and $\mathrm{pH}$ 6). For Trichoderma koningiopsis, after 4 days of incubation, the initial $\mathrm{pH}$ at $\mathrm{pH} 3, \mathrm{pH} 4, \mathrm{pH}$ 5 and $\mathrm{pH} 6$ showed the decolorization of PRMX5B at 57\%, 52\%, 34\% and 28\%, while for Trichoderma atroviride, the decolorization of PRMX5B was at $64 \%(\mathrm{pH} 3), 46 \%(\mathrm{pH} 4), 33 \%$ (pH 5) and 27\% (pH 6). After 12 days of incubation, the initial $\mathrm{pH}$ at $\mathrm{pH} 3, \mathrm{pH} 4, \mathrm{pH} 5$ and $\mathrm{pH}$ 6 showed decolorization of PRMX5B at 69\%,61\%, 43\% and 30\% respectively for Trichoderma koningiopsis. For Trichoderma atroviride, decolorization of PRMX5B was at $70 \%(\mathrm{pH} 3), 53 \%(\mathrm{pH} 4), 44 \%(\mathrm{pH} \mathrm{5)}$ and 34\% (pH 6). Next, Figure 5C and 5D showed the percentage of decolorization of RBV5R by Trichoderma koningiopsis and Trichoderma atroviride at different values of $\mathrm{pH}$. For Trichoderma koningiopsis, after 4 days of incubation, the initial $\mathrm{pH}$ at $\mathrm{pH} 3, \mathrm{pH} 4, \mathrm{pH} 5$ and $\mathrm{pH} 6$ showed the decolorization of $\mathrm{RBV} 5 \mathrm{R}$ at $61 \%, 67 \%$, $64 \%$ and $61 \%$, while for Trichoderma atroviride, the decolorization of RBV5R was at $47 \%$ $(\mathrm{pH} 3), 52 \%(\mathrm{pH} 4), 31 \%(\mathrm{pH} 5)$ and $39 \%(\mathrm{pH} 6)$. After 12 days of incubation, the initial $\mathrm{pH}$ at $\mathrm{pH} 3, \mathrm{pH} 4, \mathrm{pH} 5$ and $\mathrm{pH} 6$ showed decolorization of RBV5R at 71\%, 73\%, 70\% and $67 \%$ respectively for Trichoderma koningiopsis. For Trichoderma atroviride, decolorization of RBV5R was at $60 \%(\mathrm{pH} 3), 58 \%(\mathrm{pH} 4), 42 \%(\mathrm{pH} 5)$ and $50 \%(\mathrm{pH} 6)$. From the data obtained, it can be concluded that the optimum $\mathrm{pH}$ value for both Trichoderma koningiopsis and Trichoderma atroviride is at $\mathrm{pH} 3$. This is because the optimum $\mathrm{pH}$ was between $\mathrm{pH} 3$ and $\mathrm{pH}$ 5 , which was suitable for fungal growth and enzymatic production. The chemistry of both molecules and fungal biomass was influenced by the initial $\mathrm{pH}$ value of the dye solution [9]. 

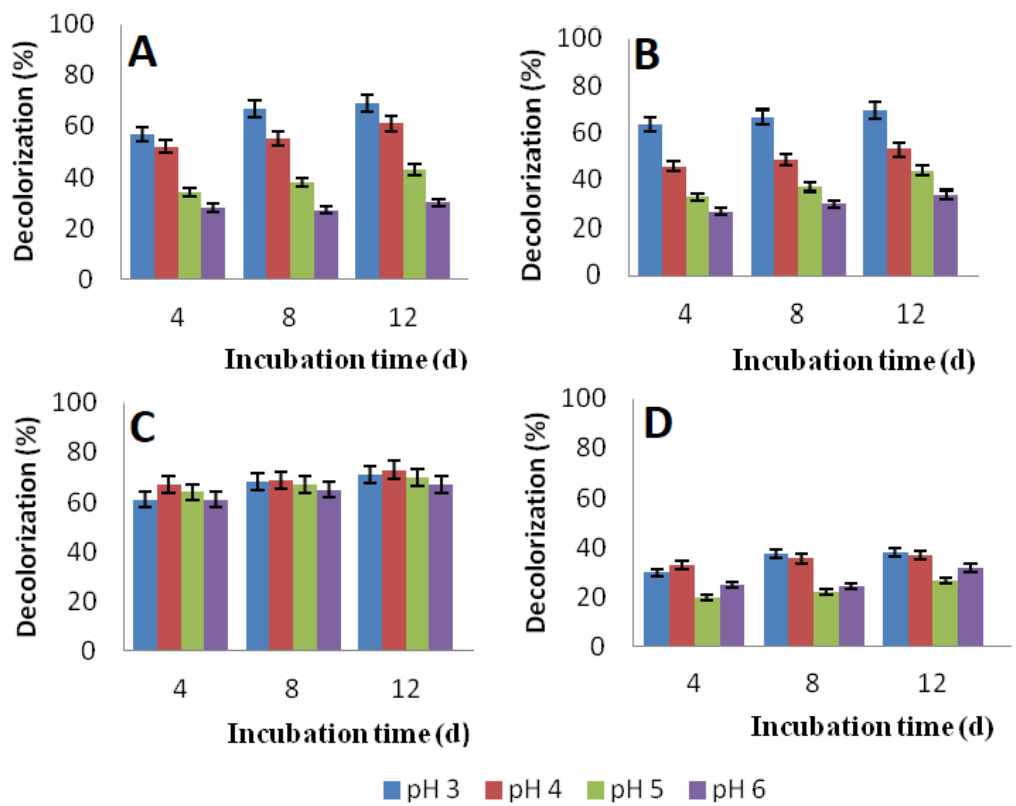

Figure 5. Effect of $\mathrm{pH}$ in decolorization of PRMX5B by Trichoderma koningiopsis (A) and Trichoderma atroviride (B); and RBV5R by Trichoderma koningiopsis (C) and Trichoderma atroviride (D).

Figure 6A and 6B show the percentage of PRMX5B decolorization at three different temperatures, $20^{\circ} \mathrm{C}, 27^{\circ} \mathrm{C}$ and $37^{\circ} \mathrm{C}$. Both Trichoderma koningiopsis and Trichoderma atroviride decolorized dye at a temperature of $20^{\circ} \mathrm{C}$ were $12 \%$ and $14 \%$, respectively, after 4 days of incubation. The percentages keep increasing after 8 days and 12 days of incubation. For Trichoderma koningiopsis, the percentage of decolorization was 19\% (8 days) and 27\% (12 days), while for Trichoderma atroviride, it was $18 \%$ and $21 \%$ respectively. Trichoderma koningiopsis decolorizes dyes up to $20 \%$ (4 days), $28 \%$ (8 days), and $40 \%$ (12 days) at $27^{\circ} \mathrm{C}$, whereas Trichoderma atroviride decolorizes dyes $11 \%, 24 \%$, and $38 \%$ at $20^{\circ} \mathrm{C}, 27^{\circ} \mathrm{C}$, and $37^{\circ} \mathrm{C}$, respectively.Trichoderma koningiopsis and Trichoderma atroviride show $49 \%$ and $46 \%$ after being incubated for 12 days. While Trichoderma koningiopsis decolorized dye up to $66 \%$ and Trichoderma atroviride decolorized dye at $60 \%$ within 4 days of incubation at $37^{\circ} \mathrm{C}$. After 12 days, the percentage of decolorization at $37^{\circ} \mathrm{C}$ increased to $75 \%$ (Trichoderma koningiopsis) and $72 \%$ (Trichoderma atroviride). While for temperature at $20^{\circ} \mathrm{C}$ after 12 days, the results obtained show that 48\% (Trichoderma koningiopsis) and 33\% (Trichoderma atroviride) of decolorization of dye, and for temperature at $27^{\circ} \mathrm{C}$, Trichoderma koningiopsis and Trichoderma atroviride can decolor dye up to $69 \%$ and $49 \%$ respectively within the same time of incubation. It can be concluded that the optimum for both Trichoderma koningiopsis and Trichoderma atroviride to decolor dye over $45 \%$ was at $37^{\circ} \mathrm{C}$. As the temperature increased, the decolorization of the dye increased. This may be because the solubility of the enzyme increased at high temperatures and then enhanced the enzymatic activity of the fungus to degrade dye. It shows that warmer conditions are the most suitable for the growth of the microbial cell [10-12].

Figure 7A and 7B show the percentage of decolorization of PRMX5B by Trichoderma koningiopsis and Trichoderma atroviride at two different conditions, with agitation and static growth. For Trichoderma koningiopsis, after 4 days of incubation, the decolorization of PRMX5B at static and shaking conditions was $18 \%$ and $25 \%$, while for Trichoderma 
atroviride, the decolorization of PRMX5B was at 10\% (static growth) and 24\% (with agitation).
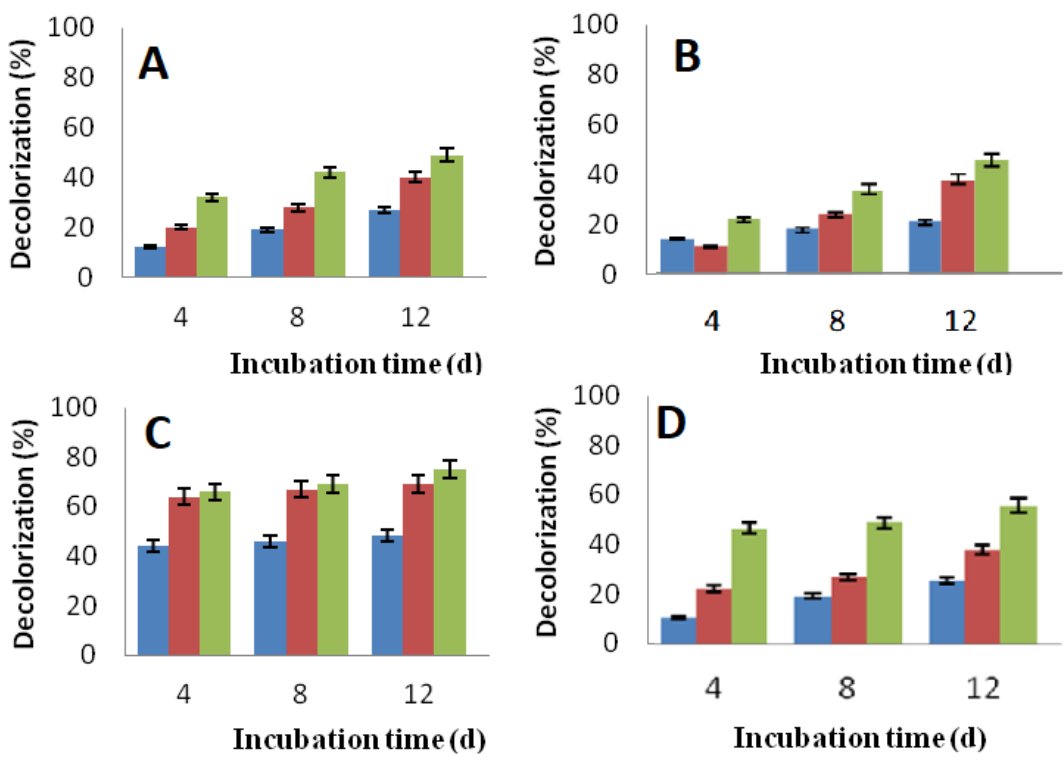

$=20^{\circ} \mathrm{C}-27^{\circ} \mathrm{C}=37^{\circ} \mathrm{C}$

Figure 6. Effect of temperature in decolorization of PRMX5B by Trichoderma koningiopsis (A) and Trichoderma atroviride (B); and RBV5R by Trichoderma koningiopsis (C) and Trichoderma atroviride (D).

After 12 days of incubation, both fungi showed a higher percentage of decolorization of dye in the shaking state compared to the static state, which was 69\% (Trichoderma koningiopsis) and 74\% (Trichoderma atroviride), while without agitation, Trichoderma koningiopsis and Trichoderma atroviride decolorized dye up to $42 \%$ and 58\%, respectively. Figure 7C and 7D show the percentage of decolorization of RBV5R by Trichoderma koningiopsis and Trichoderma atroviride at two different conditions, with agitation and static growth. For Trichoderma koningiopsis, after 4 days of incubation, the decolorization of RBV5R at static and shaking conditions was $51 \%$ and 59\%, while for Trichoderma atroviride, the decolorization of PRMX5B was 36\% (static growth) and 42\% (with agitation). After 12 days of incubation, both fungi showed a higher percentage of decolorization of dye in the shaking state compared to the static state, which was $90 \%$ (Trichoderma koningiopsis) and $71 \%$ (Trichoderma atroviride), while without agitation, Trichoderma koningiopsis and Trichoderma atroviride decolorized dye up to $79 \%$ and $42 \%$, respectively. The results obtained can conclude that agitation $(100 \mathrm{rpm})$ enhanced the decolorization of dye within the time of incubation. This is because agitation may have increased the distribution of nutrients and oxygen to the fungus, thereby promoting enzyme secretion and fungal growth. The decolorization of these synthetic dyes under static growth conditions was lower compared to with agitation conditions. This is because the growth of mycelia increased, which are rich in amino hydrophobins (which absorb the water-soluble dye) $[13,14]$. 

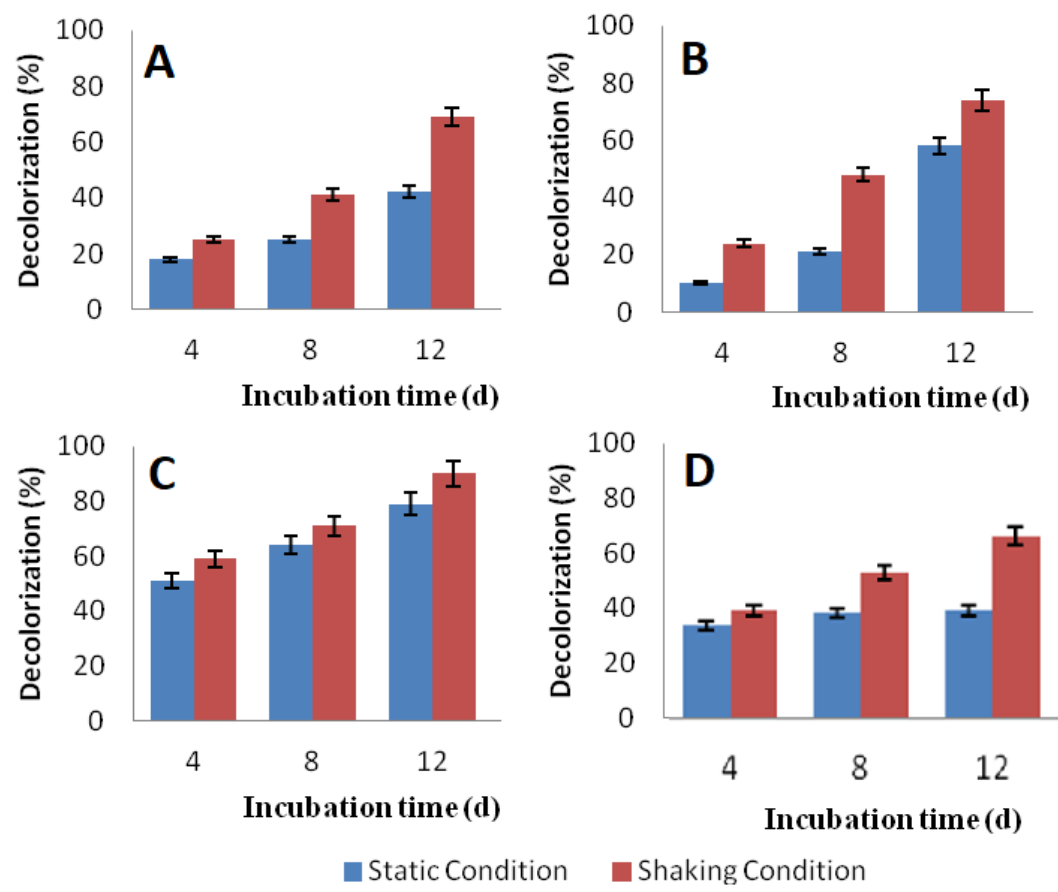

Figure 7. Effect of temperature in decolorization of PRMX5B by Trichoderma koningiopsis (A) and Trichoderma atroviride (B); and RBV5R by Trichoderma koningiopsis (C) and Trichoderma atroviride (D).

\section{Conclusions}

Based on the phylogenetic tree, fungi S1 and S2 were identified as Trichoderma koningiopsis and Trichoderma atroviride, respectively. Both fungi were able to decolorize RBV 5R and Reactive Red 2 under several parameters given, such as carbon and nitrogen sources, $\mathrm{pH}$, temperature, and agitation. This study can be improved by applying the same method to different types of dyes; studying the effect of other parameters such as metal ions, salinity, and surfactant tween 80; also, the condition of fungal growth should be monitored strictly to enhance the secrection of ligninolytic enzymes.

\section{Acknowledgements}

The authors thank Universiti Teknologi Malaysia for facilitating this work. Collaboration from Universiti Sains Islam Malaysia and King Saud University, Saudi Arabia is highly appreciated.

\section{Conflicts of Interest}

The authors declare no conflict of interest.

\section{References}

[1] Benkhaya, S.; M'rabet, S.; El Harfi, A. (2020). A review on classifications, recent synthesis and applications of textile dyes. Inorganic Chemistry Communications, 115, 107891. https://doi.org/10.1016/j.inoche.2020.107891.

[2] Tkaczyk, A.; Mitrowska, K.; Posyniak, A. (2020). Synthetic organic dyes as contaminants of the aquatic environment and their implications for ecosystems: A review. Science of The Total Environment, 717, 137222. https://doi.org/10.1016/j.scitotenv.2020.137222. 
[3] Zhou, Y.; Lu, J.; Zhou, Y.; Liu, Y. (2019). Recent advances for dyes removal using novel adsorbents: A review. Environmental Pollution, 252, 352-365. https://doi.org/10.1016/j.envpol.2019.05.072.

[4] Bulgariu, L.; Escudero, L.B.; Bello, O.S.; Iqbal, M.; Nisar, J.; Adegoke, K.A.; Alakhras, F.; Kornaros, M.; Anastopoulos, I. (2018). The utilization of leaf-based adsorbents for dyes removal: $\begin{array}{lllll}\text { A review. Journal of Molecular Liquids, 276, } & \text { 728-747. }\end{array}$ https://doi.org/10.1016/j.molliq.2018.12.001.

[5] Mostafa, A.AF.; Elshikh, M.S.; Al-Askar, A.A.; Hadibarata, T.; Yuniarto, A.; Syafiuddin, A. (2019). Decolorization and biotransformation pathway of textile dye by Cylindrocephalum aurelium. Bioprocess Biosystem Engineering, 42, 1483-1494. https://doi.org/10.1007/s00449019-02144-3.

[6] Hadibarata, T.; Syafiuddin, A.; Al-Dhabaan, F.A.; Elshikh, M.S.; Rubiyatno (2018). Biodegradation of Mordant orange-1 using newly isolated strain Trichoderma harzianum RY44 and its metabolite appraisal. Bioprocess Biosystem Engineering, 41, 621-632. https://doi.org/10.1007/s00449-018-1897-0.

[7] Yang, Q.; Tao, L.; Yang, M.; Zhang, H. (2008). Effects of glucose on the decolorization of Reactive Black 5 by yeast isolates. Journal of Environmental Sciences, 20, 105-108. https://doi.org/10.1016/S1001-0742(08)60016-9.

[8] Aracagök, Y.; Cihangir, N. (2013). Decolorization of Reactive Black 5 by Yarrowia lipolytica NBRC 1658. American Journal of Microbiological Research, 1, 16-20. http://dx.doi.org/10.12691/ajmr-1-2-1.

[9] Fu, Y.; Viraraghavan, T. (2000). Removal of a Dye from Aqueous Solution by the Fungus Aspergillus niger. Water Quality Research Journal of Canada, 35, 95-111. http://dx.doi.org/10.2166/wari.2000.006.

[10] Saratale, R.G.; Saratale, G.D.; Kalyani, D.C.; Chang, J.C.; Govindwar, S.P. (2009). Enhanced decolorization and biodegradation of textile azo dye Scarlet $\mathrm{R}$ by using developed microbial $\begin{array}{llll}\text { consortium-GR. } \quad \text { Bioresource } & \text { Technology, 2493-500. }\end{array}$ https://doi.org/10.1016/j.biortech.2008.12.013.

[11] Pietikainen, J.; Pettersson, M.; Baath, E. (2005). Comparison of temperature effects on soil respiration and bacterial and fungal growth rates. FEMS Microbiology Ecology, 52, 4958. https://doi.org/10.1016/j.femsec.2004.10.002.

[12] Tang, W.; Kuehn, T.H.; Simcik, M.F. (2015). Effects of Temperature, Humidity and Air Flow on Fungal Growth Rate on Loaded Ventilation Filters. Journal of Occupational and Environmental Hygiene, 12, 525-537. https://doi.org/10.1080/15459624.2015.1019076.

[13] Kaushik, P., \& Malik, A. (2009). Fungal dye decolorization: Recent advances and future potential. Environment International, 35, 127-141. https://doi.org/10.1016/j.envint.2008.05.010. Mahmoud, Mohamed \& Mostafa, Mohamed \&

[14] Mohamed, S.; Sobhy, N.; Nasr, M. (2017). Bioremediation of red azo dye from aqueous solutions by Aspergillus niger strain isolated from textile wastewater. Journal of Environmental Chemical Engineering, 5, 547-554. https://doi.org/10.1016/j.jece.2016.12.030.

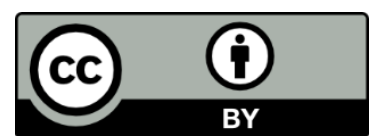

(C) 2021 by the authors. This article is an open access article distributed under the terms and conditions of the Creative Commons Attribution (CC BY) license (http://creativecommons.org/licenses/by/4.0/). 